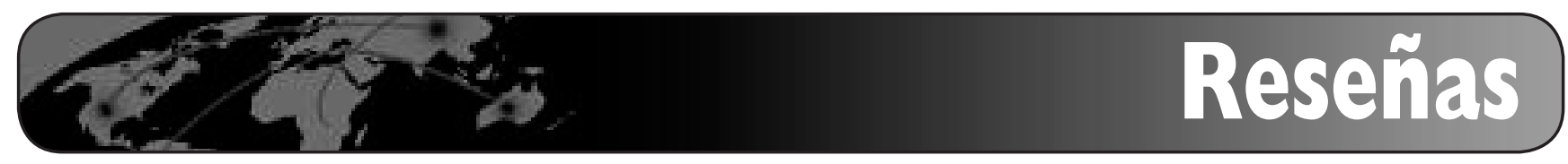

\title{
Redes de colaboración científica: análisis y visualización de patrones de coautoría (Antonio Perianes-Rodríguez, Carlos Olmeda-Gómez y Félix De-Moya-Anegón)
}

\author{
Por Benjamín Vargas-Quesada
}

\begin{abstract}
Vargas-Quesada, Benjamín. "Redes de colaboración científica: análisis y visualización de patrones de coautoría (Antonio Perianes-Rodríguez, Carlos Olmeda-Gómez y Félix De-Moya-Anegón)". Reseña de libro. El profesional de la información, 2010, mayo-junio, v. 19, n. 3, pp. 315-316.

DOI: 103145/epi.2010.may.14
\end{abstract}

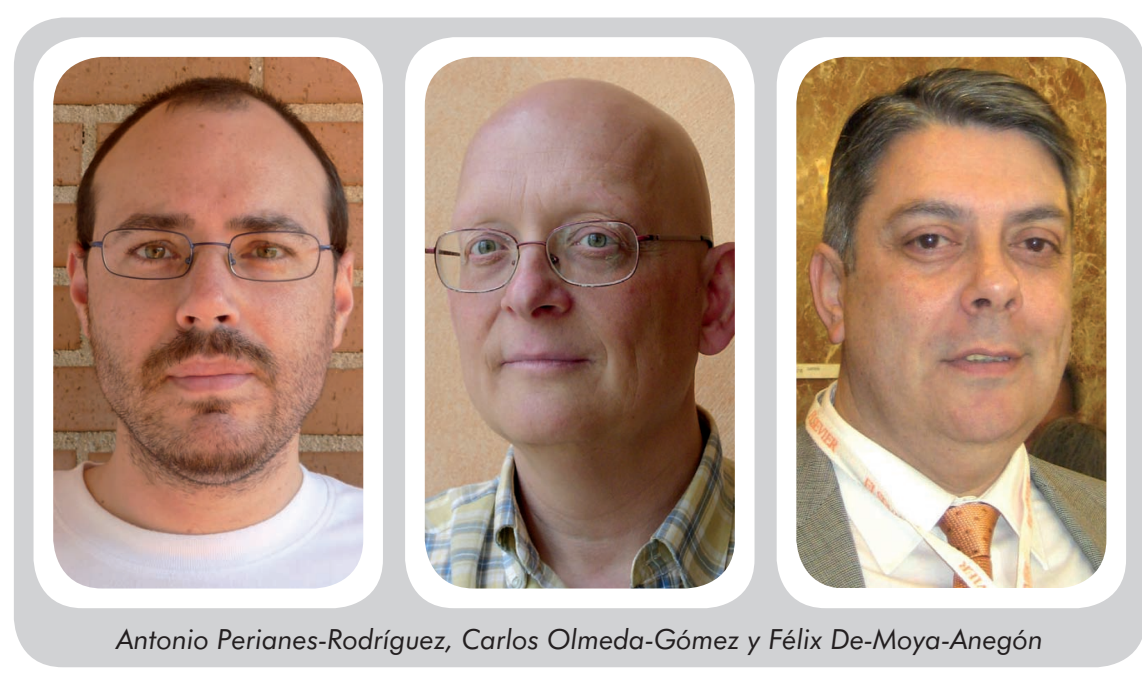

"LACOLABORACIÓNCIENTÍFICA es un fenómeno fundamental en la práctica investigadora. Aunque siempre ha existido colaboración en la ciencia, en la actualizad asistimos a un cambio significativo. Las nuevas prácticas de investigación se caracterizan por la interdisciplinaridad $y$ por el incremento de interacciones entre instituciones e individuos.

Este libro propone en primer lugar un método para la detección, identificación y visualización de grupos de investigación a partir de redes de coautoría. En segundo lugar, aborda el análisis de la colaboración científica, ampliando el enfoque tradicional del estudio de los resultados de investigación, presentando nuevos indicadores híbridos que combinan las facetas bibliométrica y el análisis estructural y de redes" (parafraseado del libro).

La obra consta de nueve amplios capítulos en los que se exponen los aspectos que hay que tener en cuenta para el análisis de grupos de investigación a partir de redes de coautoría. Por orden, además de una introducción y las conclusiones, son los siguientes: colaboración científica, grupos de investigación, visualización de la información, teoría de redes, materiales, metodología, y discusión de resultados. Les antecede un sumario y un índice de tablas, e incluye también una completa bibliografía.

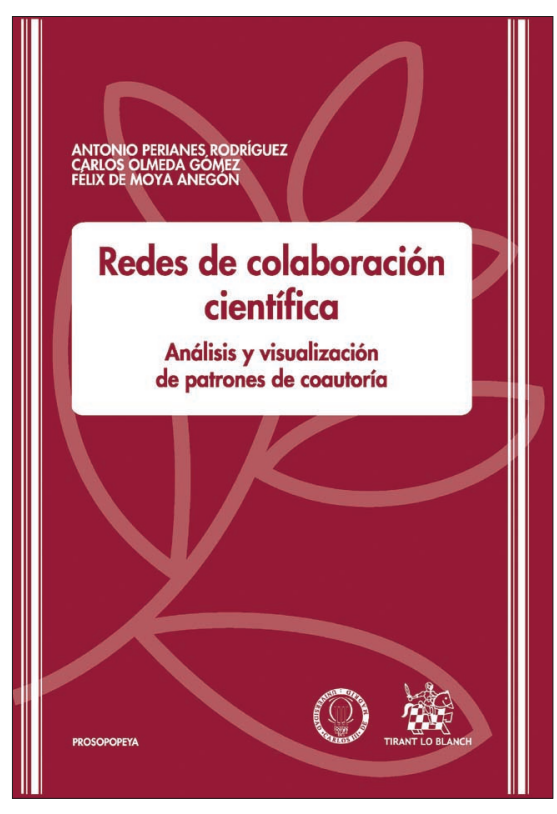

Perianes-Rodríguez, Antonio; Olmeda-Gómez, Carlos; De-Moya-Anegón, Félix. Redes de colaboración científica: análisis y visualización de patrones de coautoría. Valencia: Tirant lo Blanch, 2010, 212 pp. ISBN: 9788498767469

\section{Tipo de investigación}

El primer mérito de los autores reside en haber integrado técnicas y métodos que hasta ahora permanecían aislados. Es como el huevo de Colón: algo obvio pero que nadie hasta ahora había hecho. Comien- 
zan exponiendo cómo en los últimos años se han producido avances espectaculares en la perspectiva científica de los estudios estructurales, con origen en disciplinas como las matemáticas discretas y la teoría de grafos, la sociología, la psicología de grupos o la biología, pero también en la bibliometría, la informetría y la cibermetría, y más recientemente en la física. No obstante, aunque los hallazgos de esos estudios pueden facilitar el análisis y la toma de decisiones, se hace necesario un examen de sus dinámicas de información. Para ello los autores proponen aplicar la teoría de redes al estudio de la colaboración científica, lo cual hace posible entender la ciencia como un sistema autoorganizado.

Aunque siempre ha existido colaboración en la ciencia, en la actualidad es posible observarla, valorarla y cuantificarla. Sin embargo, desde la perspectiva de la biblioteconomía y documentación existe una escasa investigación sobre el fenómeno de la colaboración científica a través de las redes y sus posibles utilidades. Por ello, el segundo mérito de Perianes, Olmeda y De Moya es la aportación de un marco teórico y metodológico que permite la identificación, caracterización e interpretación de grupos de investigación a partir del examen y la visualización de redes de colaboración basadas en la coautoría de los documentos científicos.

La elaboración de indicadores híbridos sintéticos para la convergencia de las aproximaciones bibliométrica y estructural es su tercera y mayor aportación, que en combinación con las técnicas de visualización de información, facilitan el análisis y la toma de decisiones, así como el examen de las dinámicas de información.

\section{"El primer mérito de los autores es integrar técnicas y métodos que hasta ahora permanecían aislados"}

\section{Público al que va dirigido}

Cualquier persona implicada o relacionada con las ciencias de la información y la documentación, incluyendo por supuesto a la biblioteconomía, estará fascinada con esta nueva aproximación que pone en contraste las técnicas utilizadas para el análisis de la colaboración científica, su interpretación y la toma de decisiones.

Aunque sin entrar a discutir las razones, mencionaré algunas profesiones que se beneficiarán de este libro al estar estrechamente relacionadas con sus objetivos: investigadores analistas, bibliotecarios implicados en el servicio de referencia y búsqueda de información, analistas de sistemas que usan técnicas de modelado y de red, informáticos especializados en la visualización y representación esquemática de la información, historiadores, sociólogos, educadores (pedagogos, planificadores de planes de estudios...), políticos y gestores de políticas científicas entre muchos otros.

\section{Presentación y estilo}

El libro se presenta en una edición barata de tipo bolsillo, con pastas blandas y papel de mediana calidad, que cumple el cometido que se pretende. La impresión es buena. El tamaño de la letra adecuado. Se incluyen tablas y gráficos que armonizan y ayudan a la comprensión del texto. No se han encontrado erratas ni errores tipográficos.
El texto está escrito en español. A veces se combinan frases demasiado largas con un leguaje técnico y/o académico, pero en todo momento comprensible. Un glosario, así como una lista de abreviaturas habrían sido útiles y agradecidas por el lector.

Entre los muchos aspectos recomendables están: el uso de muchos subtítulos numerados, lo que permite hacer las secciones más cortas y una remisión al lector más fácil y rápida; el uso de diagramas/ ilustraciones y tablas; una óptima y nutrida bibliografía que constituye para los principiantes e iniciados una guía de inmersión en este nuevo campo de investigación.

\section{"Su mayor aportación son los indicadores híbridos sintéticos para la convergencia de las aproximaciones bibliométrica y estructural"'}

\section{Recomendaciones}

Se trata de un libro excelente, altamente recomendado para los iniciados en el análisis de la colaboración científica, e implicados en la toma de decisiones de políticas científicas. Pero también para aquellos que se quieran iniciar en su estudio, ya que les hará de lazarillo, mostrándoles los caminos y vericuetos de esta difícil materia.

Benjamín Vargas-Quesada. Facultad de Comunicación y Documentación, Universidad de Granada. benjamin@ugr.es 